TecnoHumanismo. Revista Científica

Diciembre 2021 - Febrero 2022

Volumen 1 / No.4

ISSN: $2710-2394$

pp. $79-111$

https://doi.org/10.53673/th.v2i2.103

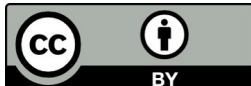

\title{
Los impuestos verdes y su relación con el derecho fundamental a un medio ambiente saludable
}

Green taxes and their relationship with the fundamental right to a healthy environment

Os impostos verdes e sua relação com o direito fundamental ao meio ambiente saudável

\section{ARTÍCULO GENERAL}

\author{
Jenny Celinda Dávila Dávila \\ jecedada@gmail.com \\ https://orcid.org/0000-0001-5965-0540 \\ Universidad Pedro Ruiz Gallo - Chiclayo \\ Lambayeque - Perú
}

\author{
John Hitler Mena Dávila \\ jmenad@pucp.edu.pe \\ https://orcid.org/0000-0002-3632-6550 \\ Universidad Pedro Ruiz Gallo - Chiclayo \\ Lambayeque - Perú
}

Recibido 07 de Junio 2021 | Arbitrado y aceptado 25 de Agosto 2021 | Publicado en 04 Diciembre 2021

\section{RESUMEN}

A partir del derrame de petróleo producido el 15 de enero de 2022 en el mar de Ventanilla por parte de la empresa REPSOL, nos formulamos la siguiente pregunta ¿Existe la necesidad de gravar con un impuesto la contaminación ambiental producida por las empresas en el desarrollo de sus actividades?, la respuesta definitivamente es que resulta un imperativo categórico gravar a loa agentes contaminantes con un impuesto que pueda resarcir el daño causado al ecosistema y al derecho fundamental a un medio ambiente saludable de las personas que viven en zonas aledañas al lugar donde se produjo el derrame de petróleo.

En el presente trabajo se realizará un análisis de la legislación comparada de Ecuador y Costa Rica, países donde se viene aplicando de manera exitosa el mecanismo de los impuestos verdes; se realizará una evaluación de los ingresos recaudados por el impuesto, cuyo propósito es financiar actividades de mitigación, lo que se traduce en la conservación del medio ambiente.

Asimismo, se evaluará el beneficio tributario de devolución del impuesto pagado para incentivar actividades como el reciclaje, lo que abre las puertas para una economía circular; adicionalmente, el involucramiento de la comunidad en los planes de conservación del ambiente, como parte de la ejecución del monto recaudado, contribuye a la eficacia del respectivo tributo.

A mayor abundamiento, los impuestos ambientales permiten internalizar, al menos parcialmente, el costo ambiental dentro del precio de los bienes, pues no es posible establecer si el monto pagado compensa el deterioro ambiental, el daño a la vida silvestre en nombre del desarrollo económico de las naciones y la afectación al derecho fundamental de gozar de un medio ambiente saludable, el mismo que se constituye como un derecho humano de tercera generación.

Palabras clave: Impuestos verdes, derecho fundamental a un medio ambiente saludable.

\section{ABSTRACT}

Based on the oil spill produced on January 15 , 2022 in the Ventanilla Sea by the REPSOL company, we asked ourselves the following question: Is there a need to tax the environmental pollution produced by companies in the development of their activities? The definitive answer is that it is a categorical imperative to levy a tax on polluting agents that can compensate for the damage caused to the ecosystem and the fundamental right to a healthy environment of the people who live in areas surrounding the place where it occurs. caused the oil spill.

In the present work, an analysis of the comparative legislation of Ecuador and Costa Rica, countries where the mechanism of green taxes has been successfully applied, will be carried out; An evaluation of the income collected by the tax will be carried out, whose purpose is to finance mitigation activities, which translates into the conservation of the environment.

Likewise, the tax benefit of refunding the tax paid will be evaluated to encourage activities such as recycling, which opens the doors for a circular economy; additionally, the involvement of the community in environmental conservation plans, as part of the execution of the amount collected, contributes to the effectiveness of the respective tax.

Furthermore, environmental taxes make it possible to internalize, at least partially, the environmental cost within the price of goods, since it is not possible to establish whether the amount paid compensates environmental deterioration, damage to wildlife in the name of the economic development of nations and the affectation of the fundamental right to enjoy a healthy environment, the same that is constituted as a third generation human right.

Keywords: Green taxes, fundamental right to a healthy environment.

\section{RESUMO}

Com base no derramamento de óleo produzido em 15 de janeiro de 2022 no Mar de Ventanilla pela empresa REPSOL, nos perguntamos: Existe a necessidade de tributar a poluição ambiental produzida pelas empresas no desenvolvimento de suas atividades? que é imperativo categórico a cobrança de um imposto sobre os agentes poluidores que possa compensar os danos causados ao ecossistema e ao direito fundamental ao meio ambiente sadio das pessoas que vivem no entorno do local onde ocorreu o derramamento de óleo.

No presente trabalho, será realizada uma análise da legislação comparada do Equador e da Costa Rica, países onde o mecanismo de impostos verdes foi aplicado com sucesso; Será realizada uma avaliação da receita arrecadada pelo imposto, cuja finalidade é financiar atividades de mitigação, o que se traduz na conservação do meio ambiente.

Da mesma forma, será avaliado o benefício fiscal de restituição do imposto pago para incentivar atividades como a reciclagem, que abre as portas para uma economia circular; adicionalmente, 0 envolvimento da comunidade em planos de conservação ambiental, como parte da execução do valor arrecadado, contribui para a efetividade do respectivo imposto.

Além disso, os impostos ambientais permitem internalizar, ao menos parcialmente, o custo ambiental no preço das mercadorias, pois não é possível estabelecer se o valor pago compensa a deterioração ambiental, danos à fauna em nome do desenvolvimento econômico das nações e a afetação do direito fundamental de desfrutar de um meio ambiente sadio, o mesmo que se constitui como direito humano de terceira geração.

Palavras-chave: Impostos verdes, direito fundamental ao meio ambiente saudável. 


\section{1.- introducción}

El incremento del deterioro medio ambiental ha llevado a que la atención de la sociedad se enfoque en medidas correctivas que lleven al desarrollo humano sostenible. Como parte de estas medidas, surge el concepto de impuestos ambientales, cuyo objetivo es ayudar a los gobiernos a cumplir sus objetivos en materia ambiental.

Países de Latinoamérica y el Caribe (LAC) han venido introduciendo este tipo de impuestos. Entre eso países destaca Costa Rica, reconocido por su buen desempeño ambiental, Ecuador, que implementó en 2011 dos impuestos ambientales cuya efectividad vale la pena identificar en aras de evaluar la conveniencia de su implementación en Perú. En este sentido, este trabajo se plantea la siguiente pregunta ¿Cuáles elementos de los tributos ambientales implementados en Ecuador y Costa Rica podrían ser considerados referentes para Perú?, considerando su efectividad en términos de conservación del medio ambiente.

Los impuestos verdes forman parte de los mecanismos para la protección del medio ambiente que buscan desincentivar prácticas nocivas para la naturaleza e incentivar el uso de energías limpias. En el Perú se incorporó un impuesto que tienen esa finalidad, el impuesto al consumo de bolsas plásticas. Sin embargo, existe aún muchos supuestos que pueden ser sometidos a imposición, como por ejemplo el derrame de petróleo producido por la empresa REPSOL o los derrames de petróleo producidos por la empresa PETROPERÚ, bajo el principio "El que contamina paga", con el propósito que el Estado cuente con los recursos idóneos y suficientes para realizar acciones concretas que reduzcan el impacto ambiental de la actividad contaminante de ciertos agentes económicos.

En el presente trabajo se realizará un análisis de la legislación comparada para poder determinar cual es la política tributaria ambiental del legislador y cual es el fin extrafiscal que se persigue con esas medidas impositivas, lo cual evidentemente tiene que tener un alto grado de correlación con los derechos humanos de tercera generación y poner al ser humano como el fin supremo de la sociedad y el Estado.

En ese orden de ideas, se considera indispensable que se comience con la creación de impuestos ambientales específicos, más allá del único vigente a la fecha, el cual es el impuesto a las bolsas plásticas. El impuesto selectivo al consumo, cuyo fin es gravar las externalidades negativas causadas por el consumo de productos como el alcohol, el tabaco 
y el combustible, puede tener la apariencia de un impuesto ambiental; sin embargo, por un tema de especialidad resultaría más apropiado que el legislador originario o el legislador derivado produzcan un impuesto específico que busque reducir las externalidades negativas en el medio ambiente, por el consumo de combustibles fósiles.

El artículo I del título preliminar de la Ley general del ambiente - Ley $\mathrm{N}^{\circ} 28611$ prescribe lo siguiente: "Toda persona tiene el derecho irrenunciable a vivir en un ambiente saludable, equilibrado y adecuado para el pleno desarrollo de la vida, y el deber de contribuir a una efectiva gestión ambiental y de proteger el ambiente, así como sus componentes, asegurando particularmente la salud de las personas en forma individual y colectiva, la conservación de la diversidad biológica, el aprovechamiento sostenible de los recursos naturales y el desarrollo sostenible del país". En ese sentido, corresponde al Estado garantizar la plena vigencia de los derechos ambientales de los ciudadanos peruano y la vía idónea para el cumplimiento de dicho fin es el uso de los impuestos para el fin extrafiscal de garantizar un ambiente saludable y equilibrado, tal como lo están haciendo en la actualidad, países como Ecuador, Costa Rica y Colombia.

\section{Marco Teórico}

En esta parte se realizará un análisis de los referentes teóricos de los impuestos ambientales, el fin extrafiscal que se busca con su implementación, el cual es garantizar la plena vigencia del derecho fundamental a un medio ambiente saludable y mantener la sostenibilidad ambiental del ecosistema peruano.

\subsection{Antecedentes ambientales}

Posterior a la revolución industrial, se evidencia el incremento de las actividades industriales, el uso de combustibles fósiles, las innovaciones de tipo tecnológico y la población mundial. Esta situación, que podría entenderse como consecuencia del desarrollo económico, ha desencadenado el incremento de emisiones de gases efecto invernadero (GEI) a la atmósfera, así como la generación de desechos de todo tipo, que generan gases tóxicos, y que, por lo general, no son reutilizables, reciclables o aprovechables. Esto también ha traído cambios en la temperatura media de la Tierra $\left(1^{\circ} \mathrm{C}\right.$ más que en la época preindustrial - Revista Semana, 2019), en la atmósfera, la hidrósfera y la litósfera, los cuales se han manifestado en la acidificación de los océanos, la deforestación y el deterioro de la biodiversidad (IDEAM, 2020). 
En este contexto, se han llevado a cabo distintas cumbres e iniciativas cuyo tema central es el desarrollo sostenible y la problemática ambiental, dentro de las que se destacan las siguientes:

a) El club de Roma (1968): en el que se reconoce que los recursos naturales no son ilimitados (Eschenhagen, 2006).

b) Conferencia de Estocolmo (1972): la cual incorpora la visión ética, social y económica en el análisis de la problemática ambiental (Eschenhagen, 2006).

c) Cumbre de la Tierra (1992): integra el desarrollo económico y la protección ambiental (Eschenhagen, 2006). Ésta dio lugar a la Convención Marco de las Naciones Unidas sobre el Cambio Climático (CMNUCC).

d) Protocolo de Kioto (1997): Creado para reducir las emisiones de gases de efecto invernadero (GEI) que causan el calentamiento global (Secretaría de Medio Ambiente y Recursos Naturales, 2016).

e) Cumbre Mundial sobre el desarrollo sostenible (2002): Dirigida a poner en práctica el desarrollo sostenible (sin dar una definición concreta de éste) (Eschenhagen, 2006).

f) Conferencia sobre el cambio climático (2007): Genera el Plan de Acción de Bali y los aspectos de mitigación (Muñoz, 2008).

g) Cumbre de Doha (2012): Se extiende el Protocolo de Kioto (Zuñiga, 2012).

h) Agenda 2030 (2015): Se lanzan los 17 Objetivos de Desarrollo Sostenible (ODS). Integra los tres pilares del desarrollo sostenible (económico, social y medioambiental) (Naciones Unidas Colombia, 2020).

i) Acuerdo de Paris (2015): Propone mantener el aumento de la temperatura mundial en este siglo por debajo de $\operatorname{los} 2^{\circ} \mathrm{C}$ con respecto a los niveles preindustriales (Naciones Unidas, 2020).

j) Cumbre sobre la acción climática (2019): Informa de las acciones que están llevando a cabo los países y de las propuestas para la conferencia de 2020 (Naciones Unidas, 2020). 


\subsection{Externalidades}

En desarrollo de sus actividades económicas, las empresas y personas ejecutan acciones que tienen impactos en otros individuos que no participan directamente de esas transacciones. Este impacto indirecto es lo que en economía se denomina externalidades, lo que demanda de la intervención estatal para corregirlas. De acuerdo con Greenwald y Stiglitz (1986), las intervenciones gubernamentales (por ejemplo, impuestos y subsidios) pueden mejorar la situación de las economías que no son eficientes en el sentido de Pareto. Las distorsiones que surgen de la información imperfecta o los mercados incompletos a menudo se muestran como externalidades, y verlas de esta manera ayuda ha identificar las consecuencias de las intervenciones gubernamentales en el bienestar.

Las externalidades pueden ser positivas (los rendimientos privados son menores que los sociales) o negativas (los costos sociales son mayores que los costos privados), dependiendo de su impacto en la sociedad y el medioambiente. La mayoría de las externalidades se clasifican como técnicas, en las cuales los efectos indirectos tienen un impacto en las oportunidades de consumo y producción de otros, pero el precio del producto no las refleja. En consecuencia, los costos/retornos privados difieren de los costos/retornos para la sociedad en su conjunto (Helbling, 2010).

\subsubsection{Instrumentos económicos y su clasificación}

Las externalidades son fallas de mercado que pueden ser corregidas mediante instrumentos económicos haciendo uso del sistema de precios. Estos instrumentos cuentan con dos enfoques clásicos: Pigou y Coase. El enfoque pigouviano propone añadir un impuesto igual al costo social marginal, lo que conducirá a un ajuste de los precios que refleje los costos sociales indirectos derivados de la actividad empresarial que termina asumiendo la sociedad (Pigou A. C., 1920). Este enfoque tiene varias implicaciones: 1. los cambios involucrados son marginales, sin embargo, el cambio climático y la biodiversidad pueden no serlo; 2 . se asume que la externalidad es lo suficientemente pequeña como para no distorsionar el mercado, sin embargo, el cambio climático y la biodiversidad tienen un efecto a gran escala, y un impuesto al carbono que es capaz de estabilizar y reducir las emisiones tendrá un papel importante en la economía en su conjunto (Helm, 2005).

Por su parte, Coase se opuso al enfoque intervencionista propuesto por Pigou y adoptó una visión fundamentada en el comportamiento del mercado, centrándose en los 
derechos de propiedad. Para Coase, las externalidades son consecuencia de la no exclusión, de modo que, si todo es propiedad de alguien, entonces la externalidad desaparece. El centro de este enfoque es la negociación entre las partes para llegar a un acuerdo de no contaminación, bajo el cumplimiento de una serie de supuestos, que no siempre son fáciles de lograr tratándose de bienes públicos (Helm, 2005).

Dado que el presente trabajo aborda la problemática ambiental y cómo los impuestos pueden aportar a la solución de esta problemática, a continuación, se describen brevemente los instrumentos económicos desde una perspectiva pigouviana para la gestión ambiental. Estos instrumentos se encuentran clasificados de la siguiente manera: Impuestos, cargos y tarifas: estos pueden tener distintas bases gravables y tarifas a aplicar, por lo que, al momento de definir un impuesto de tipo ambiental, se debe señalar el producto, servicio o actividad sobre el cual se aplica la tarifa imponible, y esto dependerá del objetivo que persiga el tributo. Los impuestos (y en particular los impuestos ambientales) admiten distintos diseños, pueden ser específicos (aplicados sobre una unidad de producto), ad valorem (aplicados como porcentaje del precio del producto gravado), o mixtos, pues combinan los dos diseños anteriores (Comisión Económica para América Latina y el Caribe (CEPAL), 2019).

Sistemas de depósito-reembolso: El consumidor paga un depósito al momento de la adquisición de un producto potencialmente contaminante. Cuando la contaminación es evitada, se efectúa el reembolso del depósito realizado. Subsidios con fines de protección ambiental: Transferencias corrientes que las unidades del gobierno pagan a las empresas o a los hogares sobre la base de los niveles de sus actividades de producción o sobre la base de las cantidades o valores de los bienes y servicios que producen, venden o importan. Sistemas de permisos transables: Cuotas, asignaciones o límites a los niveles de emisión para sectores específicos que pueden ser comercializados o transados, sujetos a una serie de reglas preestablecidas. También son utilizados para incentivar el uso eficiente de recursos naturales.

Enfoques voluntarios: son mecanismos de corrección de externalidades ambientales a través de los cuales los agentes económicos se comprometen a reducir los efectos ambientales que provocan, más allá de lo estipulado por la ley (Comisión Económica para América Latina y el Caribe, 2015). 


\subsection{Impuestos ambientales}

La obra más influyente de Pigou fue The Economics of Welfare (1920). En ella se desarrolla el concepto de externalidades y se argumenta que las externalidades negativas deberían compensarse con un impuesto, y las positivas con un subsidio. La contribución de Pigou constituye el origen de los impuestos ambientales y del principio "el que contamina paga".

Un impuesto ambiental es un medio económico para internalizar los costos ambientales de la contaminación y destrucción ecológica en costos de producción y sistema de precios, para luego distribuirlos a través de mecanismos de mercado. Por definición, los impuestos ambientales son aquellos "cuya base imponible consiste en una unidad física (o un sustituto de ella) de algún material que tiene un impacto negativo, comprobado y específico, sobre el medio ambiente" (Comisión Económica para América Latina y el Caribe, 2015, pág. 11).

\subsection{Clasificación de los impuestos ambientales}

A continuación, se enumeran los tipos de impuestos ambientales de acuerdo con la clasificación de la European Environment Agency (1996):

\subsubsection{Cargos de cobertura de costos}

Consisten en que aquellos que hacen uso del medio ambiente cubren el costo de ese uso. Dentro de esta categoría se encuentran los cargos de usuario, donde el mismo se paga por un servicio ambiental específico (por ejemplo, el tratamiento de aguas residuales); y los cargos asignados, donde los ingresos se invierten en fines ambientales, pero no en la forma de un servicio específico para el pagador del cargo (por ejemplo, ingresos para financiar servicios de reciclaje).

\subsubsection{Incentivos Tributarios}

Este tipo se establece con la única intención de cambiar el comportamiento perjudicial para el medio ambiente (fin extrafiscal). Este tipo de impuestos se fijan con base en estimaciones del costo del daño ambiental, o del ingreso necesario para lograr los objetivos ambientales. 


\subsubsection{Impuestos ambientales}

Esta categoría tiene como objetivos cambiar el comportamiento de la sociedad y recaudar ingresos para el Estado. Estos ingresos pueden usarse para financiar déficits presupuestarios o desmontar otros impuestos (European Environment Agency, 1996).

\subsection{Ventajas de los impuestos ambientales}

\subsubsection{Internalización de costos externos}

Un impuesto ambiental internaliza el costo externo de los daños ambientales, aumentando el costo de producción y reduciendo los márgenes de ganancia de las empresas, lo que obliga a los sujetos ha adoptar prácticas de producción verde (He, y otros, 2019)

\subsubsection{Eficiencia, rentabilidad y equidad}

Los impuestos ambientales permiten separar a quienes buscan la conservación del ambiente de los que pagan por contaminar. El principio de equidad se cumple si quienes pagan por el control ambiental son quienes contaminan (principio "quien contamina paga") (Panayotou, 1994).

\subsubsection{Fuente de ingresos}

Los impuestos ambientales generan ingresos que pueden gastarse en bienes públicos que mejoran la calidad ambiental u otros fines extrafiscales (Panayotou, 1994).

\subsubsection{Implementación e influencia}

Estos impuestos se implementan a través de la legislación, regulando la base imponible, la tasa y el mecanismo de devolución (He, et al, 2019). Ello hace que puedan implementarse en todo un país y les da fuerza de ley para su cumplimiento, lo que no ocurre con los enfoques voluntarios.

\subsection{Limitaciones a los impuestos verdes}

\subsubsection{Impacto ambiental incierto}

El nivel de reducción de contaminación alcanzado por un impuesto ambiental depende de la respuesta de los contaminadores individuales al impuesto. 


\subsubsection{Complejidad para las empresas}

Es necesario que las empresas recopilen información relacionada tanto con la elección de la tecnología como con el pago de impuestos ambientales.

\subsubsection{Costos de administración y ejecución}

Los impuestos ambientales requieren mecanismos para su administración y ejecución.

\subsubsection{Diferencias geográficas}

Cuando el daño ambiental varía dependiendo de la fuente, la aplicación de un impuesto uniforme puede resultar ineficiente (Smith, 1998).

\subsection{Hipótesis del doble dividendo}

Los impuestos ambientales son percibidos como un instrumento eficiente para proteger el medio ambiente, al ayudar a reducir la contaminación a través del cambio en el comportamiento de quienes contaminan (dividendo verde). Además, los ingresos recaudados por este tipo de impuestos pueden ayudar a desplazar otros impuestos de carácter distorsionante (Helm, 2005).

De esta manera, el gobierno puede cosechar un "doble dividendo", no solo propiciando un entorno más limpio, sino también un sistema impositivo menos distorsionado (Bovenberg, 1999).

Sin embargo, conforme cambia el comportamiento de los sujetos que contaminan $\mathrm{y}$, en consecuencia, el dividendo verde se incrementa, la base gravable sobre la cual recae el impuesto ambiental tiende a reducirse, con lo cual la recaudación disminuye en el largo plazo.

Según la economía del bienestar, la diferencia entre la contaminación ambiental (beneficio de corrección de la contaminación ambiental) y el costo de implementación (pérdida básica de bienestar) es el beneficio ambiental neto (efecto de bienestar básico); es decir, el "dividendo verde" del impuesto ambiental. Un impuesto ambiental internaliza los costos sociales y económicos de la contaminación y reduce el beneficio al aumentar el costo total de producción, aunque a largo plazo incentiva el cambio en el modo de producción para ahorrar recursos. Con ello se frena la degradación ambiental y se promueve la reducción de emisiones. Por otro lado, los impuestos ambientales proporcionan fondos para la política ambiental posterior (He, y otros, 2019). 
Por otra parte, hay impuestos e instrumentos económicos que distorsionan el sistema tributario, como algunos subsidios que son ineficientes. Por ello, la introducción de impuestos ambientales puede ayudar a desplazar o contrarrestar el carácter distorsionante de este tipo de instrumentos, generando un doble dividendo (Shah y Larsen, 1992).

\subsection{Efectividad de los impuestos ambientales}

los impuestos ambientales pueden considerarse efectivos si cumplen con los objetivos por los cuales se originaron. La evaluación de este concepto se hace bajo dos criterios: efecto ambiental, el cual consiste en el resultado del impuesto sobre el uso de los recursos o la contaminación (donde se incluye el uso del recaudo en planes de mejoramiento o compensación ambiental); y el efecto incentivador, que consiste en comparar la tasa de impuestos con la reducción de los costos de contaminación marginal, con lo que se alienta a los contribuyentes a reducir la contaminación, principalmente debido a los diferenciales entre la tasa impositiva y el costo de las medidas de reducción. La efectividad ambiental de los impuestos ambientales se basa en la evidencia sobre sus beneficios ambientales (European Environment Agency, 1996).

El artículo de He et al., (2019) proporciona evidencia empírica de que, en general, los impuestos ambientales tienen efectos significativos en la reducción de emisiones a corto plazo tanto en los países miembros de la OCDE como en las provincias administrativas El artículo de He et al., (2019) proporciona evidencia empírica de que, en general, los impuestos ambientales tienen efectos significativos en la reducción de emisiones a corto plazo tanto en los países miembros de la OCDE como en las provincias administrativas.

\subsection{Análisis de la legislación comparada en materia impositiva ambiental}

Para establecer cuan efectiva es la tributación verde, supone comparar la situación de un país en particular con lo experimentado por aquellas naciones o regiones con mayores desarrollos en la materia. Al respecto, los países de la Unión Europea introdujeron impuestos ambientales en la década de los noventa, por lo que tras cerca de 30 años después de su implementación, se pueden observar los resultados obtenidos.

Dinamarca, Finlandia, Alemania, Países Bajos, Suecia y Reino Unido son algunos de los casos de éxito que lograron introducir e incrementar impuestos ambientales, y cuyo 
recaudo ha sido utilizado para compensar las reducciones en los impuestos laborales y cargas sociales y para subsidiar energías renovables.

En la Unión Europea, la participación de estos impuestos oscila entre el 2\% y 3\% del PIB, y están compuestos por impuestos sobre la energía, el transporte y la contaminación $(75 \%, 20 \%$ y $5 \%$ sobre el total recaudado por impuestos ambientales, respectivamente). En términos del impacto ambiental alcanzado por estos impuestos se cuentan, entre otros, con la desaparición casi por completo del combustible con plomo y la reducción de residuos, del consumo de agua y de las fugas de agua desde su fecha de implementación (CEPAL, 2015).

La situación de América Latina y el Caribe (LAC) dista de la europea, debido a que la región presenta abundancia relativa de recursos naturales y enfrenta graves problemas de pobreza y desigualdad. La abundancia de recursos, las necesidades de desarrollo y el rápido crecimiento demográfico, han resultado en la prevalencia de los objetivos sociales sobre los ambientales.

Debido a esto, los impuestos ambientales en LAC representan en promedio el 1,3\% del PIB; en 2016, solo Costa Rica y Honduras superaban el 2\% (CEPAL, 2019). Adicional a lo anterior, la incorporación de impuestos ambientales para-LAC debe considerar que la elasticidad precio de combustibles es baja, debido a la fase de desarrollo económico en la que se encuentra, y el potencial carácter regresivo que pueden tener sobre la distribución del ingreso (CEPAL, 2019).

\subsection{Impuesto Verdes en Ecuador}

En medio del contexto de la problemática ambiental, en 1999 el Gobierno de Ecuador expidió la Ley de Fomento Ambiental (Congreso Nacional de Ecuador, 1999), la cual dicta una normativa jurídica ambiental, determina las obligaciones, responsabilidades, niveles de participación de los sectores público y privado en la gestión ambiental y señala los límites permisibles, controles y sanciones en esta materia. Esta Ley fue reformada mediante Suplemento del Registro Oficial No. 583 del 24 de noviembre de 2011, en el que fue publicada la Ley de Fomento Ambiental y Optimización de los Ingresos del Estado, con la que se realizan cambios sobre el Régimen Tributario Interno. Ecuador cuenta con dos impuestos ambientales: el impuesto a los consumos especiales e IVA diferenciado para vehículos menos contaminantes y el impuesto redimible a las 
botellas plásticas no retornables (IRBP). Desde noviembre de 2011 y hasta agosto de 2019 estuvo vigente el impuesto ambiental a la contaminación vehicular (IACV).

\subsubsection{Impuesto ambiental a la contaminación vehicular (IACV)}

El IACV grava la contaminación del ambiente producida por el uso de vehículos motorizados de transporte terrestre. Éste fue derogado mediante el Segundo Suplemento del Registro Oficial No.19, del 16 de agosto 2019, bajo dos argumentos, el primero, que no había cumplido su objetivo de impulsar una conducta social que fuera responsable con el ambiente, y segundo, que los ingresos de este tributo perjudicaron el bolsillo de la clase trabajadora. Pese a lo anterior, en el presente trabajo se analizarán los componentes y resultados obtenidos por este tributo durante el tiempo que estuvo vigente.

En la tabla 1 se podrá apreciar cuales fueron los objetivos del impuesto, los sujetos pasivos de la relación jurídico tributario, la base imponible, la tasa y el destino de los fondos obtenidos; pudiéndose apreciar que los mismos cumplen con el principio de reserva de ley, al estar los elementos del tributo ambiental descritos en una norma de rango de ley. Así mismo, se advierte los objetivos extrafiscales del tributo; es decir, no sólo se sustenta en la necesidad de recaudación, sino en el imperativo categórico de garantizar un medio ambiente saludable para que el sujeto de derechos pueda alcanzar su máxima realización.

\section{Tabla 1}

\section{Elementos del IACV Elementos del IACV}

\begin{tabular}{ll}
\hline & $\begin{array}{l}\text { Reducir la contaminación ambiental producida por el uso } \\
\text { de vehículos. }\end{array}$ \\
Cbjetivos & $\begin{array}{l}\text { Cambiar los patrones de consumo hacia vehículos de } \\
\text { menor cilindraje. } \\
\text { Incentivar el uso de transporte público. }\end{array}$ \\
\hline \multirow{3}{*}{ Sujeto Pasivo } & $\begin{array}{l}\text { Las personas y sociedades propietarias de vehículos } \\
\text { motorizados de transporte terrestre. Están exonerados los } \\
\text { vehículos eléctricos. }\end{array}$ \\
Base imponible & $\begin{array}{l}\text { Cilindraje que tiene el motor del respectivo vehículo, en } \\
\text { centímetros cúbicos. } \\
\text { Cuenta Corriente Única del Tesoro Nacional. Los recursos } \\
\text { recaudados se han invertido en el mejoramiento de la } \\
\text { calidad de los combustibles y en la construcción de la } \\
\text { Refinería del Pacífico para producir combustibles EURO 5. } \\
\text { Cilindraje de autos y motos }\end{array}$ \\
\hline
\end{tabular}




$\begin{array}{ll}\text { Menor a } 1500 & \$ 0.00 \\ 1501-2000 & \$ 0.08 \\ 2001-2500 & \$ 0.09 \\ 2501-3000 & \$ 0.11 \\ 3001-3500 & \$ 0.12 \\ 3501-4000 & \$ 0.24 \\ \text { Más de 4000 } & \$ 0.35\end{array}$

Factor de ajuste dependiendo de la antigüedad del vehículo y su tecnología, entre $-20 \%$ y $20 \%$.

Nota. Extraído de la ley Tributaria de Ecuador.

\subsubsection{Impuesto redimible a las botellas plásticas no retornables}

La producción de plásticos se incrementó exponencialmente desde 1950 y solo el $8 \%$ de estos desechos son reciclados (La vanguardia, 2020), lo cual representa un elevado nivel de contaminación ambiental derivado de su producción. Esta situación representa el origen del IRBP, pues, en la exposición de motivos del decreto que lo regula se señala que "uno de los mayores contaminantes que existen por sus compuestos químicos para su fabricación, son las botellas plásticas, ya que para su descomposición toman alrededor de entre 100 a 1.000 años" (República de Ecuador, 2011).

\section{Tabla 2}

Elementos del IRBP

\begin{tabular}{ll}
\hline Objetivos & $\begin{array}{l}\text { 1. Disminuir la contaminación ambiental. } \\
\text { 2. Estimular el proceso de reciclaje. }\end{array}$ \\
\hline \multirow{2}{*}{ Sujeto } & $\begin{array}{l}\text { 1. Los embotelladores de bebidas contenidas en botellas plásticas; } \mathrm{y}, \\
\text { 2. Quienes realicen importaciones de bebidas contenidas en botellas } \\
\text { plásticas. } \\
\text { Número de unidades embotelladas. El impuesto será devuelto cuando } \\
\text { Base }\end{array}$ \\
$\begin{array}{l}\text { se retorne el envase plástico al embotellador. } \\
\text { los recursos } \\
\text { Tarifa }\end{array}$ & Los fines productivos y de desarrollo del Estado Ecuatoriano \\
\hline
\end{tabular}

(República Ecuador, 2011)

\subsection{Costa Rica}

\subsubsection{Generalidades}

Costa Rica cuenta con distintos impuestos verdes y tarifas orientadas al medio ambiente, entre los que se encuentran: impuesto forestal, timbre pro parques nacionales, 
timbre de vida silvestre, tasas por importación y exportación de plantas y animales, tasa por servicio de agua potable, tasa por servicios de recolección de basura, limpieza de caños, vías públicas, mantenimiento de parques, zonas verdes, y otros, tasa por explotación de minas y canteras (González Espinoza \& Rodríguez Berrón, 2008), pago por servicios ambientales, canon de aprovechamiento de aguas, canon de vertidos, impuesto único sobre los combustibles, y el impuesto sobre la propiedad de vehículos automotores, embarcaciones y aeronaves (Vargas Alfaro, 2016).

Dada la multitud de impuestos ambientales, su recaudo con respecto al PIB es de los más altos que tiene la región. Este trabajo se centrará en los resultados obtenidos por el impuesto forestal, tasa por servicio de agua potable, pago por servicios ambientales, canon de aprovechamiento de aguas, canon de vertidos y el impuesto único sobre los combustibles, en la medida que se encuentran tributos con características similares a los que se pretenden analizar para Colombia.

\subsubsection{Impuesto forestal}

Este impuesto hace parte de la política forestal de Costa Rica, relacionada con el manejo, conservación y desarrollo sostenible de los bosques, tanto del sector público como privado.

Tabla 3

Elementos del Impuesto forestal

\begin{tabular}{|c|c|}
\hline Objetivos & Financiamiento de actividades de la Administración Forestal. \\
\hline Sujeto & $\begin{array}{l}\text { Personas físicas o jurídicas, propietarias de centros de } \\
\text { industrialización primaria de madera, o que brinden servicio de } \\
\text { aserrío a terceras personas sin contar con un centro de } \\
\text { industrialización en punto fijo, y aquellos que importen madera. }\end{array}$ \\
\hline Base & Valor de venta en el mercado de la madera en trozas \\
\hline $\begin{array}{l}\text { Destino de los } \\
\text { recursos }\end{array}$ & $\begin{array}{l}\text { Está destinado a distribuirse entre instituciones que se dedican a } \\
\text { la conservación de los bosques, tales como la Administración } \\
\text { Forestal del Estado, la Oficina del Contralor Ambiental, la } \\
\text { Oficina Nacional Forestal y Consejos Regionales Ambientales, } \\
\text { entre otros. }\end{array}$ \\
\hline Tarifa & $\begin{array}{l}3 \% \text { del valor de transferencia del mercado de la madera en } \\
\text { trozas, precio que es determinado por la Administración Forestal } \\
\text { del Estado. }\end{array}$ \\
\hline
\end{tabular}

Fuente: (República de Costa Rica, 1996) 


\subsubsection{Pago por servicios ambientales}

El PSA corresponde a una tasa o cobro que se realiza para el reconocimiento de los servicios prestados por los propietarios de bosques y plantaciones ambientales, en relación con la mitigación de las emisiones de gases con efecto invernadero, y por la protección y el desarrollo de la biodiversidad.

\section{Tabla 4}

Elementos del PSA

\begin{tabular}{|c|c|}
\hline Objetivos & $\begin{array}{l}\text { Compensar al daño medioambiental ocasionado por la } \\
\text { deforestación y el cambio de uso de la tierra. }\end{array}$ \\
\hline Sujeto & Los usuarios de los servicios públicos de agua y energía \\
\hline Base & $\begin{array}{l}\text { El PSA es variable de acuerdo con el proyecto aprobado o al } \\
\text { servicio prestado }\end{array}$ \\
\hline $\begin{array}{l}\text { Destino de los } \\
\text { recursos }\end{array}$ & $\begin{array}{l}\text { Protección de zonas privadas que comprenden áreas estratégicas, } \\
\text { protección de zonas privadas, cuyos propietarios deseen someter } \\
\text { sus inmuebles, a la conservación y protección, compra de } \\
\text { inmuebles privados situados en áreas protegidas, pago de gastos } \\
\text { operativos y administrativos necesarios para el mantenimiento de } \\
\text { las áreas protegidas, financiamiento de acueductos rurales, que } \\
\text { demuestren la sostenibilidad del recurso agua. }\end{array}$ \\
\hline Tarifa & $\begin{array}{l}\text { Porcentaje equivalente al costo del servicio brindado y a la } \\
\text { dimensión del programa o proyecto aprobado. }\end{array}$ \\
\hline
\end{tabular}

Fuente (República de Costa Rica, 1998)

\subsection{Resultados Obtenidos por los impuestos ambientales objeto del análisis}

\subsubsection{Tasa compensatoria por aprovechamiento forestal maderable en} bosque natural

Los recursos recaudados con la TAFM ayudan en el Manejo Forestal Sostenible de los bosques naturales que abastecen de madera al país, en especial los bosques del Chocó biogeográfico y el Amazonas. Con la implementación de esta tasa se busca la reducción de la tala ilegal y establecer reglas claras de juego para el acceso a esta materia prima. En ese sentido, se necesita una política tributaria ambiental en el Perú que busque una adecuada protección a los bosques frente a la potencial afectación producida por la actividad extractiva y la actividad comercial realizada por los agentes económicos en busca de la generación de riqueza, según se puede apreciar en la figura 1, existe un incremento de la recaudación con fines extrafiscales. 
Figura 1

Impuesto recaudado en millones de pesos constantes

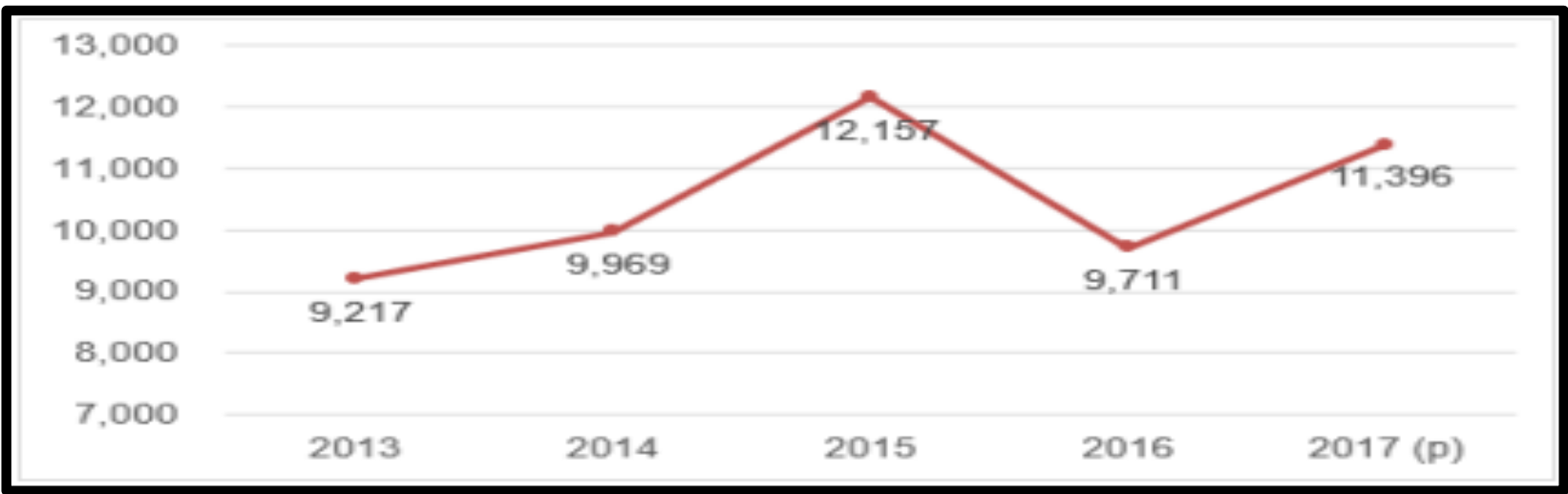

Por otro lado, de 2002 a 2019 Colombia perdió 1,50 millones de hectáreas (Mha) de bosque primario húmedo, lo que representó el 36\% del total de su cobertura arbórea. El área total de bosque primario húmedo en Colombia disminuyó 2.7\% en este período. El 33\% de la pérdida de masa forestal se dio en áreas en las que predomina la deforestación causada principalmente por la agricultura itinerante y por elaboración de materias primas, según se puede apreciar en la figura 2.

\section{Figura 2}

Pérdida anual de cobertura arbórea por deforestación

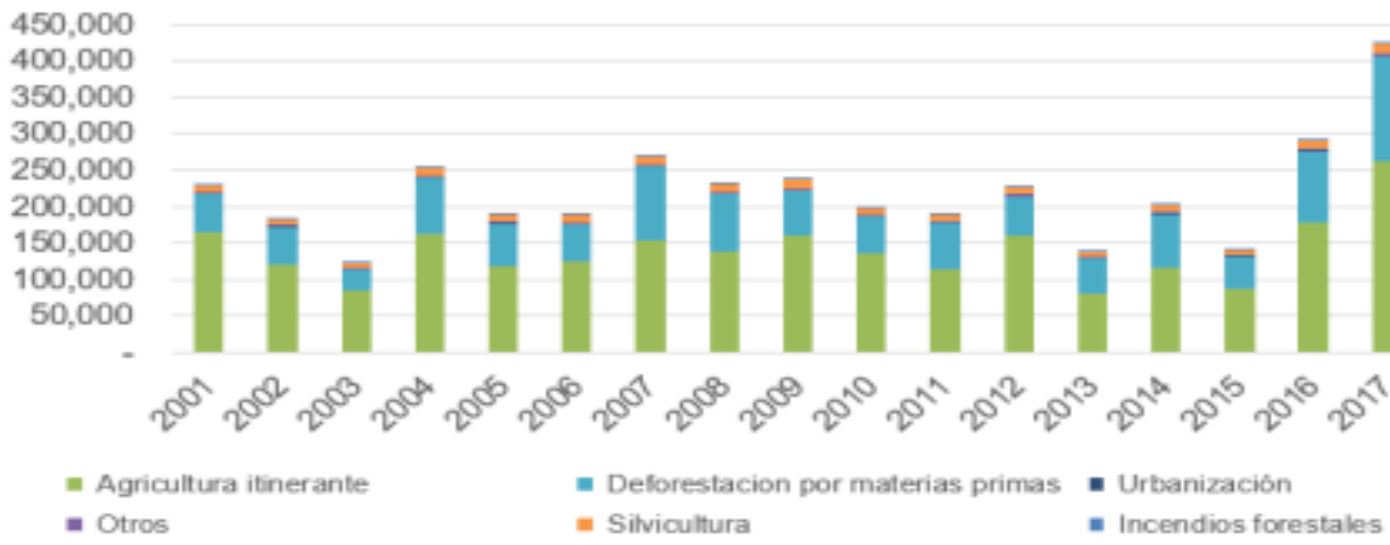

El incremento del recaudo de la TAFM guarda concordancia con el incremento de deforestación en los últimos años. Sin embargo, con los recursos recaudados no se observa que se reinvierta lo suficiente en reforestación, para compensar la pérdida de cobertura arbórea. Dado que la tasa es recaudada y administrada por las corporaciones 
autónomas regionales, actualmente no se dispone de una base de información que centralice el uso del recaudo a nivel nacional, lo cual es una limitante a esta investigación y un aspecto a mejorar por parte del Gobierno, para tener mayor control de los recursos recaudados y su adecuada utilización. Dentro de los aspectos positivos de la TAFM se destaca la intención de reducir la tala ilegal y asignar un valor al recurso maderable.

\subsection{Ecuador}

\subsubsection{Impuesto ambiental a la contaminación vehicular}

El monto recaudado por este impuesto tuvo un comportamiento estable entre 2013 y 2016, y presentó una fuerte caída en 2017. Con los recursos recaudados el Estado Ecuatoriano invirtió en la construcción de la Refinería del Pacífico para producir combustibles EURO 5, mejorando así la calidad de este.

\section{Figura 3}

Impuesto recaudado en millones de USD (precios constantes base 2012)

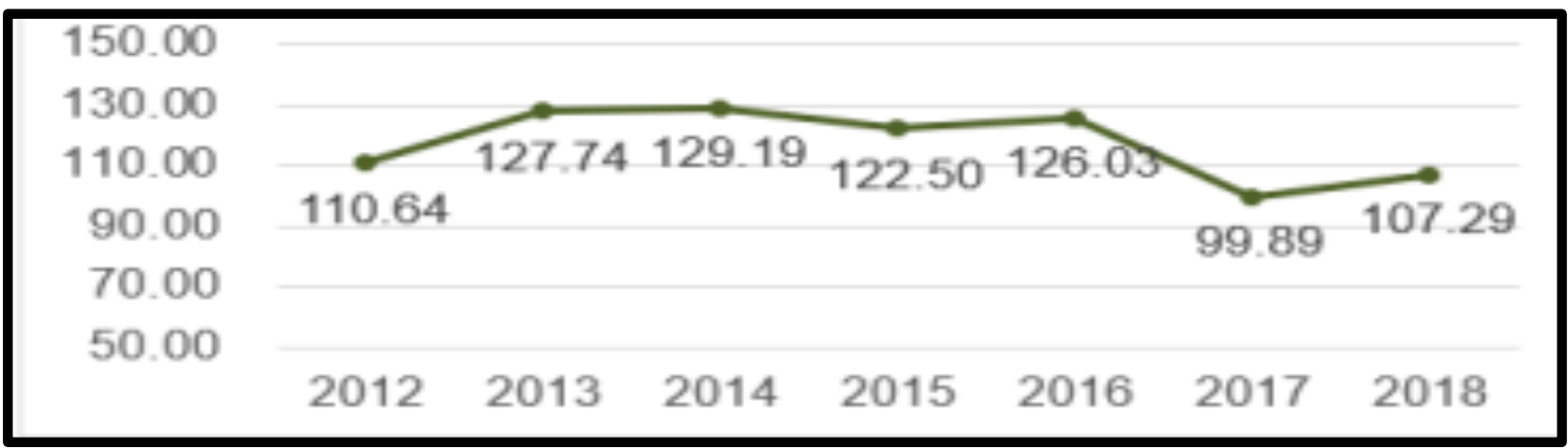

Dado que la aplicación de este impuesto dependía de la antigüedad y el cilindraje y los vehículos híbridos tenían un tratamiento preferencial, a continuación, se muestran las tendencias asociadas a estas características, según los vehículos matriculados en Ecuador. También se presenta el recaudo de este impuesto en los años en que estuvo vigente.

\subsubsection{Impuesto redimible a las botellas plásticas no retornables}

El recaudo de este impuesto se constituye en un fondo con el que se financia la devolución a los consumidores que retornen los envases plásticos para su posterior reutilización, haciendo uso del reciclaje. Así, se podría decir que el impuesto cumple con su objetivo sí el valor que se recauda es devuelto. 
Figura 4

Impuesto recaudado en millones de USD y su devolución (precios constantes base 2012)

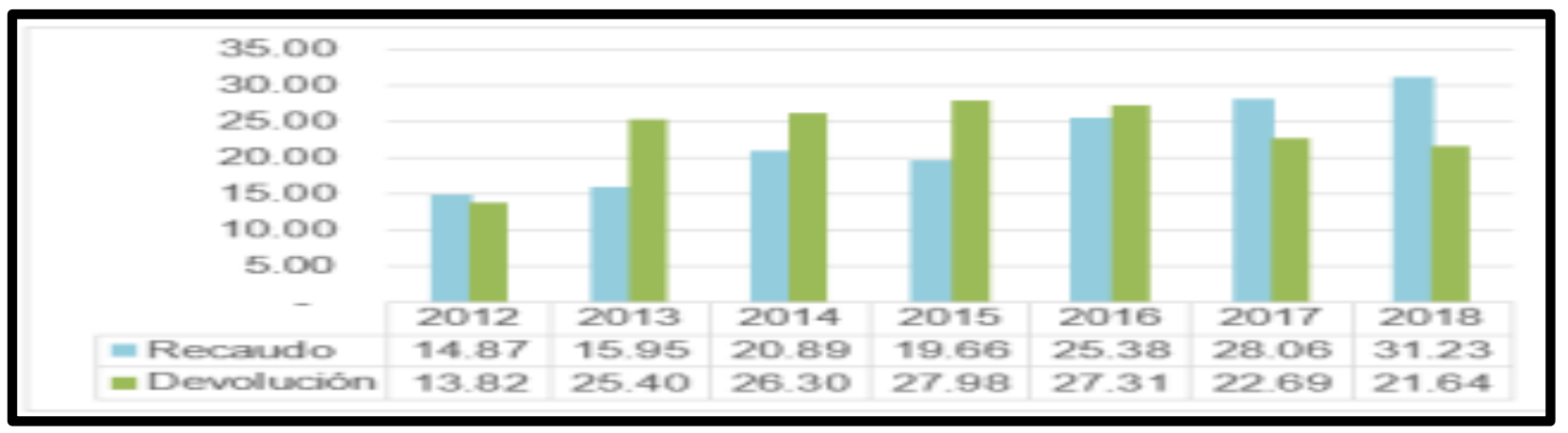

Como se aprecia en la figura, efectivamente lo que se recauda se devuelve, es más, se ha devuelto más de lo recaudado, esto debido a que antes de la aplicación del impuesto había botellas plásticas por las que no se había pagado el impuesto en mención. Lo anterior se refuerza con la siguiente figura:

Figura 5

Botellas plásticas reportadas vs recuperadas

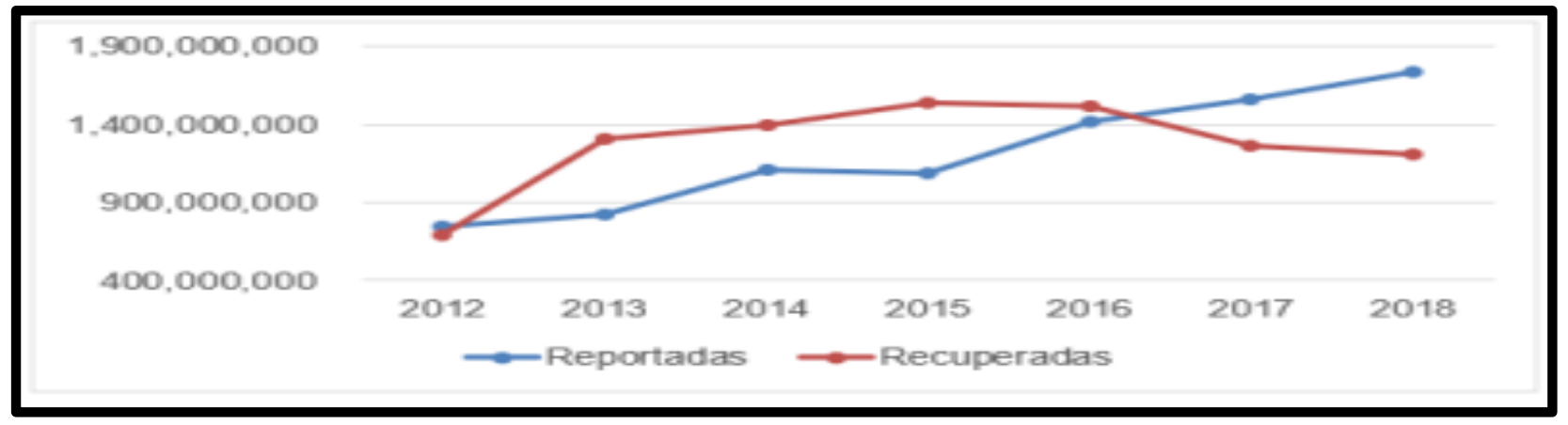

Por otra parte, el comportamiento de los hogares frente al reciclaje es positivo. En la figura se puede apreciar que a partir del 2013 la tendencia a reciclar los residuos en general, y los residuos plásticos en particular, es creciente, pasando del $22 \%$ y $20 \%$ en 2013 al $52 \%$ y $38 \%$ en 2018 , respectivamente. 
Figura 6

Hogares que clasificaron residuos

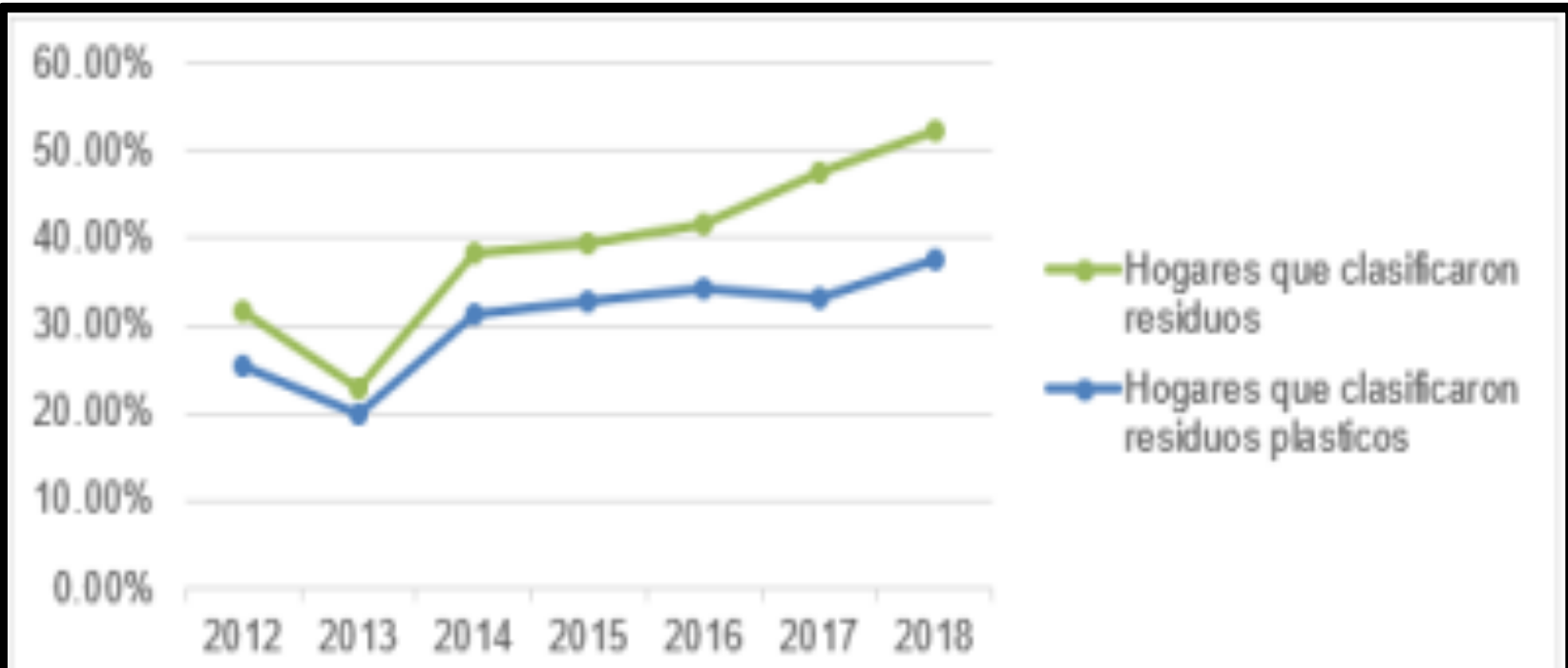

De acuerdo con estas estadísticas es posible inferir que la introducción del IRBP es uno de los factores que ha incidido en incrementar la cultura del reciclaje en Ecuador. Sin embargo, el impuesto es susceptible de mejora por cuanto puede extenderse a otros residuos plásticos de un solo uso para promover la economía circular.

\subsection{Costa Rica}

\subsubsection{Impuesto forestal}

El recaudo por este impuesto corresponde al 0,03\% de los ingresos tributarios de Costa Rica, y tiene como destinación especifica el financiamiento de programas de recuperación forestal y conservación de los bosques. 
Figura 7

Impuesto recaudado en millones de colones (precios constantes base 2008)

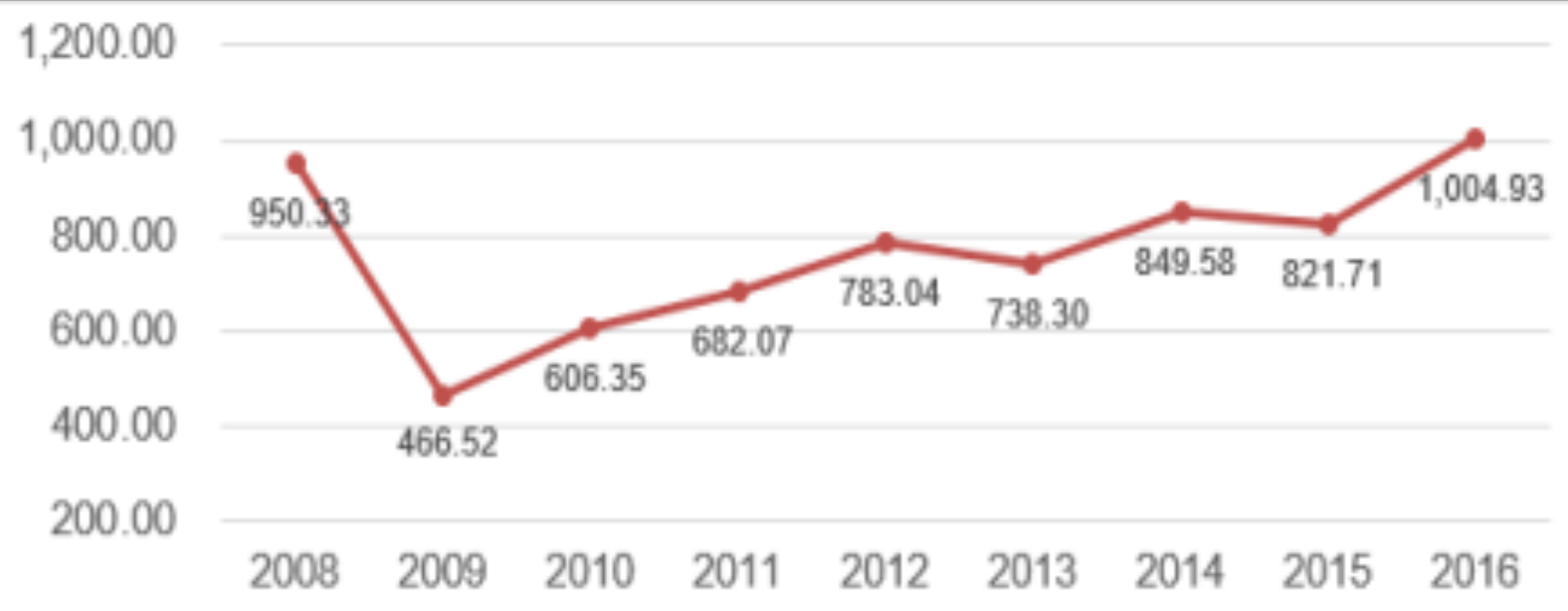

\subsubsection{Pago por servicios ambientales}

El impuesto recaudado por PSA es 10 veces más de lo que corresponde al impuesto forestal, lo cual constituye un ingreso importante para la financiación de programas ambientales para este país.

\section{Figura 8}

Monto presupuestado y ejecutado PSA en millones de colones (precios constantes base 2010)

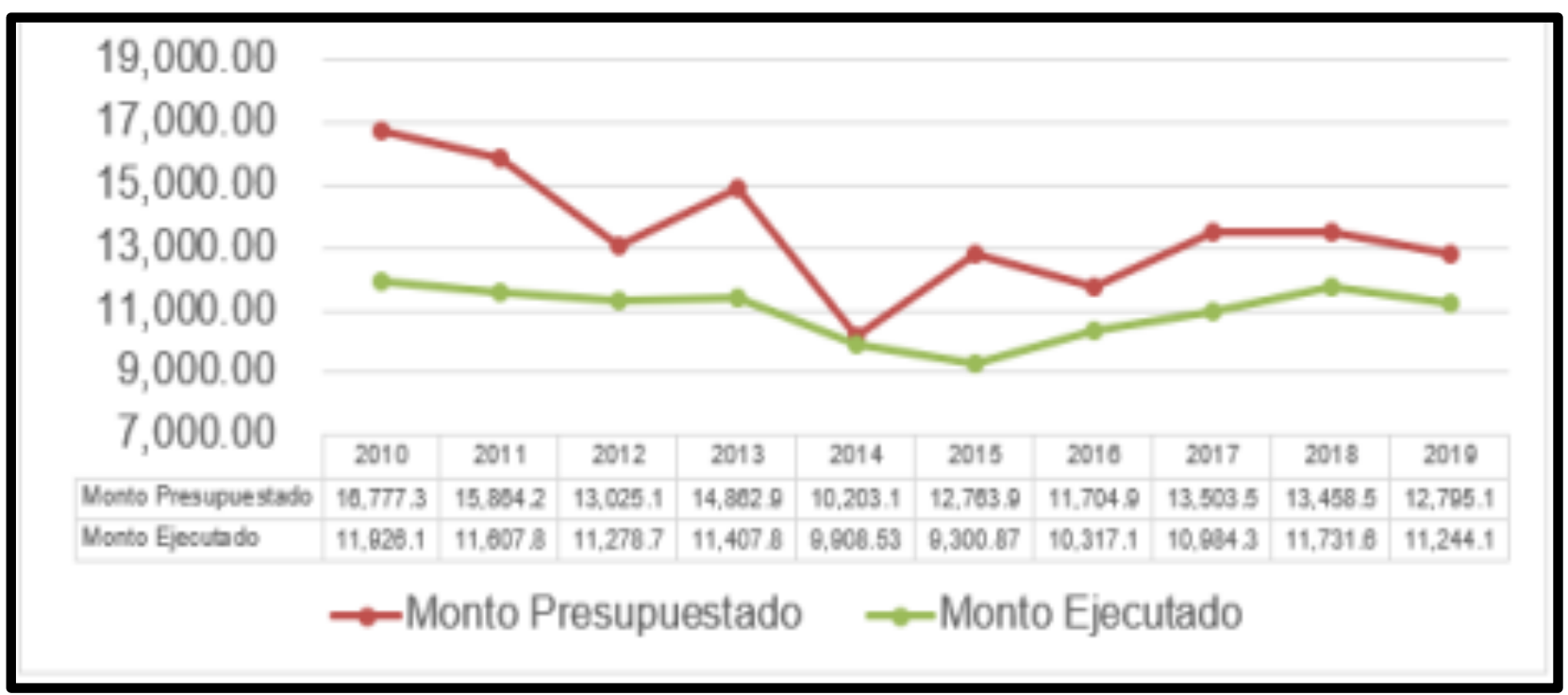


La cantidad de contratos que se suscriben con el PSA tiene un comportamiento relativamente constante, lo cual muestra que es un instrumento reconocido y utilizado por los costarricenses con un buen nivel de aceptación (total contratos 17,525 entre 1997 y 2018). Con el PSA el país ha mejorado su efectividad en el control de la tala ilegal y la conservación del bosque, así como la reducción de la deforestación.

\section{Figura 9}

Número de contratos de PSA

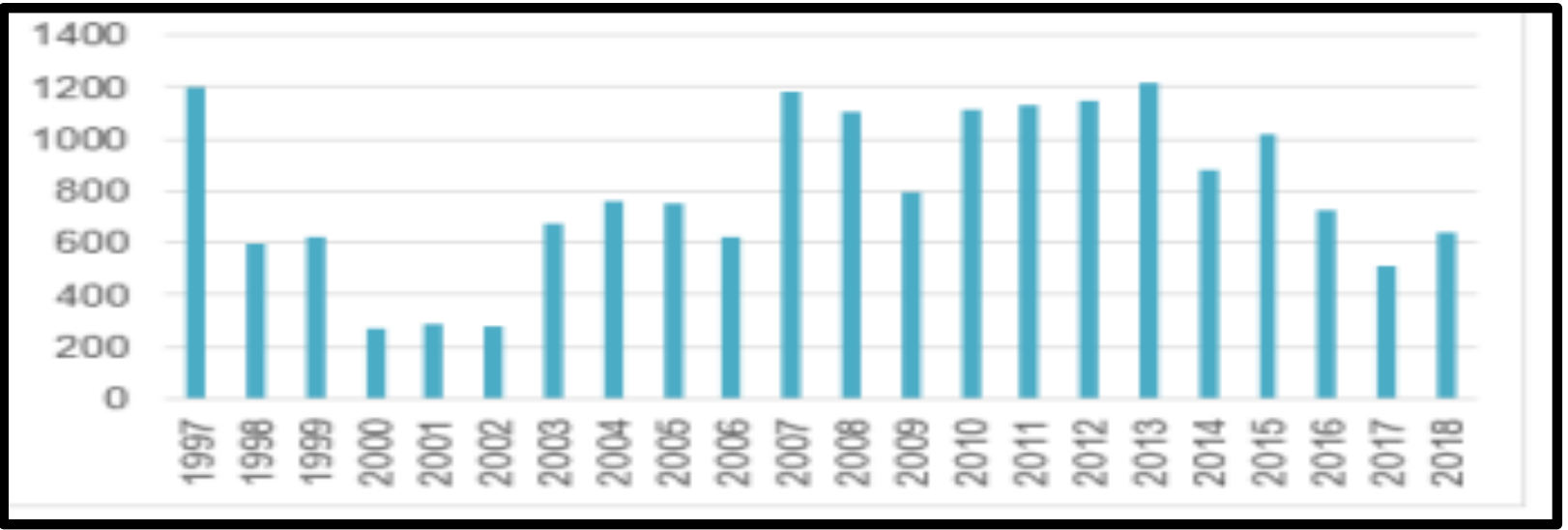

Con ayuda del PSA, Costa Rica ha logrado proteger más de 710 mil hectáreas de bosque, reforestar cerca de 50 mil hectáreas y manejar sosteniblemente 30 mil hectáreas de bosque (datos al cierre de 2010) (Porras et al., 2012).

Figura 10

Área sometida a PSA (hectáreas)

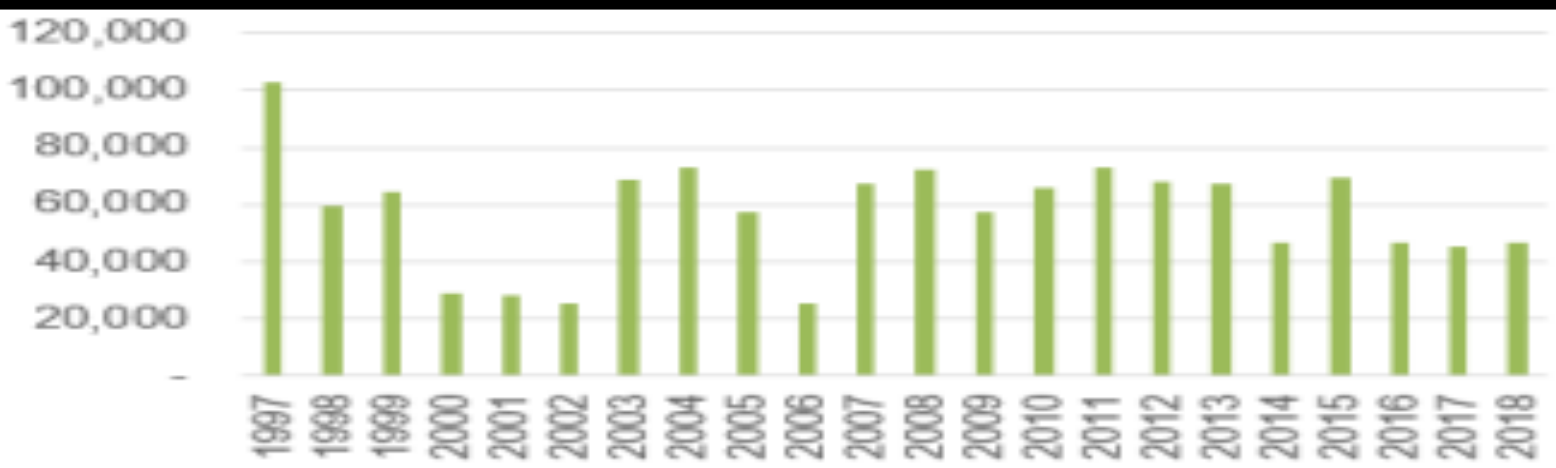

El total de hectáreas sometidas a PSA, entre 1997 y 2018 fue de 1,256,261, lo cual contribuye con la regulación del uso de zonas forestales, teniendo un efecto positivo en la conservación ambiental de Costa Rica. Dentro de los aspectos favorables del PSA se 
destaca que es un programa con amplia aceptación entre la población costarricense, lo cual le da mayor legitimidad y respaldo al instrumento. Por otra parte, el Gobierno Central tiene control sobre la administración de estos recursos.

\subsubsection{Canon aprovechamiento de aguas}

Dado que este canon se aplicó de forma gradual por 7 años y luego de este periodo se empezó a cobrar al 100\%, el país logró pasar de un monto de recaudo del impuesto insignificante a uno aceptable. El CAA le permite a Costa Rica cumplir el objetivo de generar recursos económicos para financiar a largo plazo una gestión sostenible del recurso hídrico. El número de pozos legales perforados también se ha incrementado de manera sostenida.

Figura 11

Impuesto recaudado en miles de USD (precios constantes base 2006)

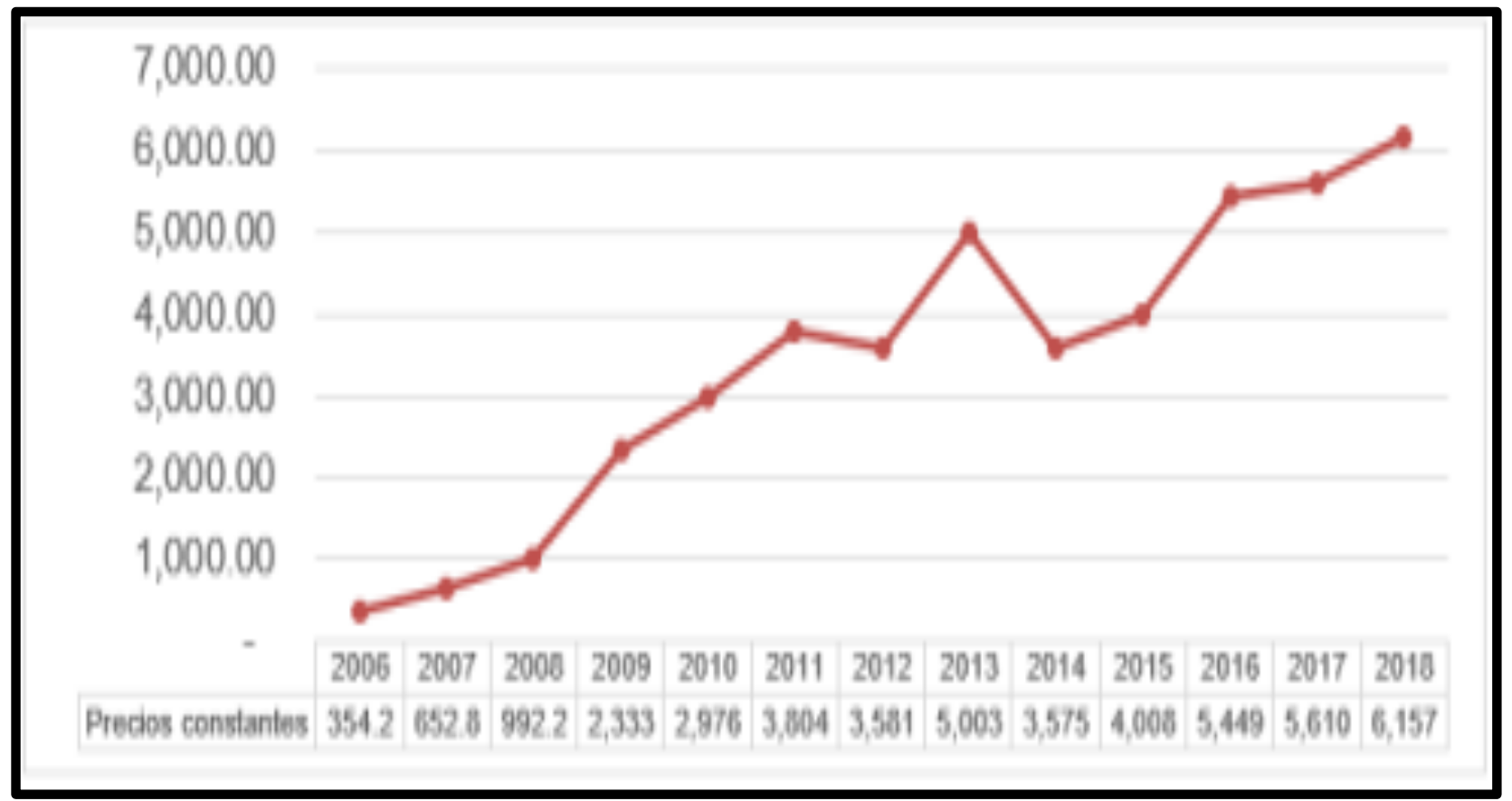

\subsubsection{Canon de vertidos}

El impuesto recaudado por el CAV es un valor que ha permanecido relativamente constante desde 2010, de acuerdo con el reporte de la Dirección de Agua. Esto puede deberse a que cuando se reglamentó este canon se fijó un monto máximo a cobrar para un periodo de 6 años. 
Figura 12

Impuesto recaudado en miles de USD (precios constantes base 2009)

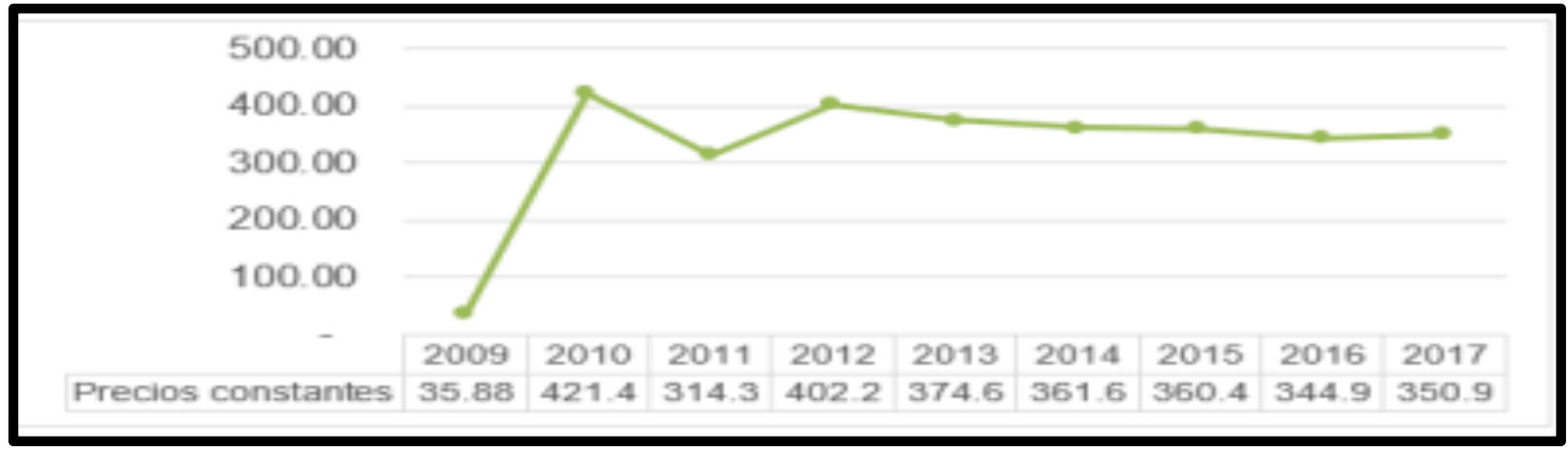

En el 2016 inició el plan nacional de monitoreo de la calidad de los cuerpos de agua superficial, con el propósito de clasificar la calidad del agua en las principales cuencas hidrográficas (MINAE, 2017). No obstante, el monitoreo en el país ha sido escaso y con estudios que no han integrado un enfoque ecosistémico de calidad (Mena-Rivera et al., 2018).

\subsubsection{Impuesto único sobre los combustibles}

Este impuesto no fue concebido como uno de tipo ambiental. Sin embargo, se muestra a continuación el comportamiento de su recaudo y del consumo de energía.

A valores constantes, el recaudo de este impuesto se ha mantenido relativamente estable entre 2002 y 2014. A partir de 2015 se observa un incremento sostenido en el recaudo. En línea con lo anterior, el tipo de energía más consumido en Costa Rica proviene de los hidrocarburos, cuyo consumo también ha permanecido constante desde 2005, lo cual es un buen signo pues sugiere que para soportar la demanda de energía que implica el crecimiento económico se está haciendo un uso más eficiente de la misma o se está sustituyendo con otras fuentes.

\subsection{Impuesto Verdes en el Perú}

En el Perú no existen Tributos Verdes y la implementación de los mismos es un imperative categórico, para el Desarrollo del tema ambiental de modo que se desincentiven las actividades que afecten el derecho constitucional a gozar de un medio ambiente sano y saludable. Así lo señala Yacolca (2006) al mencionar, que en muchos países como Ecuador, Colombia y Costa Rica se han establecido tributos ambientales, pero que nuestro país no ha asumido el reto hasta el momento y de esta forma pueda 
solucionar el problema de la contaminación, y reaccionar de una manera más efectiva a las externalidades negativas causadas por los agentes económicos, como por ejemplo el reciente caso de REPSOL.

Por lo tanto, en el Perú el único antecedente normativo específico en relación a los tributos verdes es la Ley $\mathrm{N}^{\circ} 30884$, la misma que lejos de desincentivar el consumo de bolsas plásticas por parte de los consumidores finales, ha generado un mecanismo alternativo de generación de ingresos para las empresas que antes entregaban gratuitamente dichos productos. La ley no debe establecer sólo un gravamen impositivo más alto para desincentivar el consumo; sino, debió prohibir su uso como pasa en países de la comunidad europea, donde el consumidor tiene la cultura de llevar una bolsa amigable con el medioambiente al momento de realizar sus compras en los supermercados, a la fecha debería estar prohibida la venta de bolsas plásticas que no son amigables con el medioambiente.

En relación al impuesto vehicular que es recaudada por los gobiernos locales, el sujeto pasivo del impuesto es el propietario del vehículo nuevo; es decir, los propietarios de vehículos con antigüedad mayor a tres años están inafectos al pago del impuesto vehicular, cuando dichas unidades vehiculares con las que mayor contaminación producen al medio ambiente. Por lo tanto, existe una necesidad latente de modificar el supuesto gravado y generar una justicia impositiva ambiental en relación con el impuesto vehicular.

Otro impuesto, que podría tener ciertas particularidades de un impuesto ambiental es el impuesto selectivo al consumo. Sin embargo, como se ha venido diciendo a lo largo del presente artículo, resulta un imperativo categórico la creación de impuestos ambientales específicos que tengan la capacidad de garantizar la plena vigencia del derecho fundamental a un medio ambiente saludable. A mayor abundamiento, el Selectivo al Consumo es un impuesto que el legislador derivado ha delegado la facultad de modificar la cuantía de la tasa al poder ejecutivo de manera perpetua, por lo que se advierte vicios de constitucionalidad en relación a la reserva de ley.

\section{3.- MÉTODO}

El presente trabajo de investigación es de enfoque cualitativo de tipo no experimental y de corte trasversal, donde se utiliza como instrumento el análisis de la legislación comparada de Ecuador, Costa Rica y Colombia en el extremos de los tributos 
ambientales, con el propósito de evaluar su eficacia en el rol de Estado de garantizar la plena vigencia de los derechos humanos de tercera generación, reconocidos en los instrumentos internacionales, en la constitución política del Perú y en la normativa ambiental.

Inductivo: Mediante este método se recopiló diversos conceptos teóricos y enfoques doctrinarios respecto a los tributos ambientales para identificar y tomar nota de sus características y finalidades.

Analítico: El estudio realiza el análisis de la necesidad de crear impuestos ambientales específicos que garanticen la plena vigencia del derecho a gozar de un medio ambiente saludable y compatible con los compromisos asumidos por el Perú a nivel internacional en el extremo de la reducción de la emisión de carbono.

Comparativo: Mediante la aplicación de este método se analizó y comparó las legislaciones tributarias de otros países que poseen tributos ambientales, para poder evidenciar la necesidad de crear impuestos ambientales específicos que se encuentren contenidos en una ley que busque garantizar la plena vigencia de los derechos ambientales.

\section{4.- RESULTADOS}

\subsection{Resultado 1}

En los países de Ecuador, Costa Rica y Colombia se advierte la existencia de impuestos ambientales específicos que buscan garantizar un medio ambienta saludable para sus ciudadanos. Así mismo, se advierte que el legislador tributario originario establece en la ley los supuestos gravados de manera específica, la base imponible, la cuantía del impuesto y la finalidad de dicho impuesto, con el objetivo de evitar que dichos recursos sean utilizados para otros fines.

En el Perú, más allá del impuesto a las bolsas plásticas creado por la Ley $\mathrm{N}^{\circ}$ 30884, no existe un impuesto específico que grave las externalidades negativas causadas por los agentes económicos en detrimento del medio ambiente. Se podría decir, que existen seudos impuestos ambientales como: el impuesto selectivo al consumo; sin embargo, este impuesto no solo grava las externalidades negativas en el medio ambiente, sino, en la salud de los consumidores y la sociedad, por lo que, no resulta apropiado que la regulación de un impuesto ambiental se realice a través de un impuesto genérico. 
En el Perú, no existe un impuesto que grave las emisiones de carbono producidas por los agentes económicos, a pesar que el Perú forma parte de la iniciativa internacional que busca la reducción de la emisión de carbono de los países miembros del acuerdo de Paris.

\section{5.- CONCLUSIONES}

5.1 Se debe crear Tributos Ecológicos, desarrollando los temas del Precio al Carbono y los Mercados de Carbono, para ir incorporándonos de manera progresiva a las políticas ambientales de los países de la región y de tendencia internacional, para lo cual resulta un imperativo categórico el impuesto a la emisión de carbono y la creación de incentivos tributarios para las empresas que inviertan en tecnología verde y asuman sus compromisos ambientales.

5.2 Se debe crear un impuesto que grave la contaminación ambiental de los vehículos usados con una antigüedad mayor a tres años, porque, en la actualidad, dichas unidades vehiculares son las más contaminantes y se encuentran exentos sus propietarios, se gravámenes impositivos.

5.3 Se debe crear un impuesto forestal y un impuesto al uso del agua por parte de las grandes empresas, quienes en la actualidad buscan aprovecharse de la posición garantista del Tribunal Constitucional en el extremo de los elementos constitutivos del tributo en relación al uso de las aguas subterráneas.

5.4 Se debe otorgar incentivos tributarios inmediatos a las empresas que renueven su parque automotor con vehículos eléctricos y amigables con el medio ambiente, pudiendo llegar la deducción al 175\% de la inversión realizada en un determinado ejercicio fiscal.

5.5 Los agentes económicos reaccionan de manera favorable a los incentivos tributarios, por lo cual, resulta un imperativo categórico para el Estado su aplicación en beneficio de los agentes económicos que adapten sus procesos a las políticas medio ambientales del Estado.

5.6 El derecho fundamental a un medio ambiente saludable y equilibrado, es un derecho humano de tercera generación protegido por instrumentos internacionales en los cuales el Perú es parte. Así mismo, nuestra constitución política del Perú garantiza el ejercicio de dicho derecho fundamental y es deber del Estado promover las políticas públicas necesarias para garantizar su plena vigencia. 
5.7 El Estado acorde con la coyuntura internacional y la normativa de protección ambiental que tenemos en el Perú, se debe comprometer a las empresas a realizar la extracción de los minerales del subsuelo de forma responsable y amigable con el medio ambiente, evitando actividades como el Fracking que se llevan a cabo en las zonas de la Selva, en primer lugar porque hay una contingencia futura de no saber cómo va a degenerar la fractura del subsuelo y en segundo lugar porque dicha actividad genera gran contaminación y por lo tanto, nociva y en contra de los Tratados Internacionales.

5.8 Finalmente, los impuestos pueden ser usados con fines extrafiscales de acuerdo con la jurisprudencia del Tribunal Constitucional. Sin embargo, resulta indispensable la creación de tributos ambientales específicos que guarden armonía con la plena vigencia del derecho a un medio ambiente saludable y los compromisos internacionales asumidos por el Perú.

\section{6.- REFERENCIAS}

Andía, Juan (2019), Manual de Derecho Ambiental, Perú: Ediciones “Arte y Pluma”

Arevalo, R. (2018). La Industria y sus efectos en el cambio climático Global. Revista científica de investigación actualización del mundo de las ciencias, 2 (2), 559-611. Recuperado de: https://www.redalyc.org/pdf/181/18120706003.pdf

Bovenberg, L. (1999). Green tax reformsand the double dividend: an updated reader's guide. International and public finance, 421-443.

Comisión Económica para América Latina y el Caribe (CEPAL). (2015). Impuestos verdes Viabilidad y posibles impactos en el Uruguay. Santiago de Chile: Naciones Unidas.

Comisión Económica para América Latina y el Caribe (CEPAL). (2019). Panorama fiscal de América Latina y el Caribe: Políticas tributarias para la movilización de recursos en el marco de la Agenda 2030 para el Desarrollo Sostenible. Santiagode Chile: Naciones Unidas.

Comisión Económica para América Latina y el Caribe (CEPAL). (2019). Panorama Fiscal de América Latina, 2019. Santiago: (LC/PUB.2019/8-P).

Congreso de la República de Colombia. (13 de Diciembre de 1990). Ley 43 de 1990. Colombia. 
Congreso Nacional de Ecuador. (30 de Julio de 1999). Ley No 37/1999, de gestión ambiental. Ecuador: RO 245.

Corporación Autónoma Regional. (27 de Septiembre de 2020). Tasa por Uso de Agua (TUA). Obtenido de Sitio web de la CAR: https://www.car.gov.co/vercontenido/2419

Dirección de Agua Ministerio de Ambiente y Energía. (23 de noviembre de 2017). Mecanismos Institucionales para la GIRH en Costa Rica. 9na Conferencia Centroamericana de Legisladores del Recurso Hídrico. Ciudad de Panamá, Panamá.

Dirección de Impuestos y Aduanas Nacionales. (31 de enero de 2020). Resolución número 000009. Bogotá, Colombia.

El Espectador. (8 de febrero de 2018). En Colombia se usan 2 millones 714 mil bolsas plásticas al día. El Espectador.

El Espectador. (9 de enero de 2019). Contraloría cuestiona uso del recaudo de bolsas plásticas e impuestos al carbono. Redacción Economía, págs. https://www.elespectador.com/noticias/economia/contraloria-cuestiona-usodelrecaudode-bolsas-plasticas-e-impuestos-al-carbono/.

El Espectador. (9 de junio de 2020). La plata del impuesto al carbono que se le embolató a Minhacienda. Redacción Medio Ambiente, págs. https://www.elespectador.com/noticias/medio-ambiente/mas-de-400000millonesdel-impuesto-al-carbono-andan-embolatados/

El Espectador. (9 de mayo de 2020). Obtenido de https://www.elespectador.com/noticias/actualidad/cuantos-kilos-de-plasticoseconsumen-en-colombia-articulo-823132

El Heraldo. (4 de Julio de 2019). En Colombia el uso de bolsas plásticas se redujo 53\%. El Heraldo.

Eschenhagen, M. L. (2006). Las cumbres ambientales internacionales y la educación ambiental. Oasis, 39-76.

García Arbeláez, C., Barrera, X., \& Gómez, R. y. (2015). El ABC de los compromisos de Colombia para la COP21. Bogotá: WWF-Colombia.

Greenwald, B., \& Stiglitz, J. (1986). Externalities in economies with imperfect information and incomplete markets. The quarterly journal of economics, 229-264. 
He, P., Ning, J., Yu, Z., Xiong, H., Shen, H., \& Jin, H. (2019). Can environmental tax policy really help to reduce pollutant emissions? An empirical study of a panel ARDL model based on OECD countries and China. Sustainability.

Helbling, T. (2010). What Are Externalities? What happens when prices do not fully capture costs. Finance \& Development, 48-49.

Helm, D. (2005). Economic Instruments and Environmental policy. The Economic and Social Review, 205-228.

IDEAM, PNUD, MADS, DNP, CANCILLERÍA. (2018). Segundo Informe Bienal de Actualización de Colombia a la Convención Marco de las Naciones Unidas para el Cambio Climático (CMNUCC). Bogotá.

IDEAM. (07 de 09 de 2020). Conceptos básicos del cambio climático. Obtenido de Sitio web IDEAM: http://www.cambioclimatico.gov.co/otras-iniciativas

IDEAM. (2019). Estudio Nacional del Agua 2018. Bogotá: Ideam.

La vanguardia. (3 de mayo de 2020). Obtenido de https://www.lavanguardia.com/natural/20170719/424210992121/balance mundialproduccion-plasticos-residuos.html

Malaver, E. (2016). Implementación de Tributos Ambientales en el Perú como una medida de protección al medio ambiente. (tesis de diploma). Universidad Nacional de Trujillo, Trujillo, Perú.

Ministerio de Ambiente y Desarrollo Sostenible. (2 de agosto de 2018). Decreto 1390. Bogotá, Colombia: República de Colombia.

Ministerio de Ambiente y Desarrollo Sostenible. (26 de Septiembre de 2020). Home: Convención Marco de Naciones Unidas Para el Cambio Climático CMNUCC: Historia de Colombia frente al cambio climático. Obtenido de Sitio web de minambiente: https://www.minambiente.gov.co

Ministerio de Ambiente y Energía (MINAE). (2016). Canon de aprovechamiento de agua: 10 años invirtiendo en el recurso hídrico. Heredia: Proyecto Humedales, SINAC / PNUD.

Ministerio de medio ambiente y desarrollo sostenible. (30 de noviembre de 2020). Instrumentos Económicos: Ministerio de medio ambiente y desarrollo sostenible. 
Obtenido de https://www.minambiente.gov.co/index.php/negocios-verdesysostenibles/instrumentos-economicos

Ministerio del Ambiente del Ecuador. (2018). Informe Nro. 1 Indicadores Ambientale de los Objetivos de Desarrollo Sostenible. Categorización y homologación - Ecuador. Quito.

Mohajan, H. (2019). The First Industrial Revolution: Creation of a New Global Human Era. Journal of Social Sciences and Humanities, 377-387.

Muñoz, M. (10 de Junio de 2008). Cambio Climático y la cumbre de Bali. Obtenido de Ecología Política: https://www.ecologiapolitica.info/?p=5351

Naciones Unidas Colombia. (13 de Septiembre de 2020). Agenda 2030. Obtenido de https://nacionesunidas.org.co/onu-colombia/agenda-2030/

Naciones Unidas. (13 de Septiembre de 2020). Asuntos que nos importan: Cambio climático. Obtenido de Sitio web de Naciones Unidas: https://www.un.org/es/sections/issues-depth/climate-change/index.html

Navarro, M. (2019). El impuesto sobre las emisiones de fuentes fijas y su inserción en el sistema tributario chileno. Revista de Derecho de la Pontificia Universidad Católica de Valparaíso, 52, 195-224. Recuperado desde: https://scielo.conicyt.cl/pdf/rdpucv/n52/0718-6851-rdpucv-00303.pdf

Panayotou, T. (1994). Economic instruments for environmental management and sustainable development. International Environment Program Harvard Institute for International Development Harvard University.

Pigou, A. C. (1920). The economics of welfare. London: Macmillan and Co., Limited.

Plazas, Mauricio (2005), Derecho de la Hacienda Pública y Derecho Tributario 2da Edición, Editorial Temis S.A.

Porras, I., Miranda, M., Barton, D., \& Chacón-Cascante, A. (2012). DE RIO A RIO+: Lecciones de 20 años de experiencia en servicios ambientales en Costa Rica. Londres: International Institute for Environment and Development.

República de Colombia. (15 de Marzo de 2018). Documento CONPES 3918. Estrategia para la implementación de los objetivos de desarrollo sostenible (ODS) en Colombia. Bogotá, Colombia. 
República de Colombia. (20 de octubre de 2020). Artículo 512-15 Estatuto Tributario Nacional. Estatuto Tributario de los Impuestos Administrados por la Dirección General de Impuestos Nacionales. Colombia.

República de Colombia. (26 de Mayo de 2015). Decreto 1076 de 2015. Decreto Único Reglamentario del Sector Ambiente y Desarrollo Sostenible. Bogotá, Colombia.

República de Costa Rica. (13 de febrero de 1996). Ley forestal No. 7575. Costa Rica.

República de Costa Rica. (20 de diciembre de 2019). Decreto ejecutivo $N^{\circ} 42128$.

Reglamento del canon ambiental por vertidos. Costa Rica.

República de Costa Rica. (30 de abril de 1998). Ley de Biodiversidad No. 7788. Costa Rica.

República de Costa Rica. (30 de enero de 2006). Decreto ejecutivo No. 32868. Canon por concepto de aprovechamiento de aguas. Costa Rica.

República de Costa Rica. (9 de julio de 2001). Ley No. 8114. Ley de Simplificación y Eficiencia Tributarias. Costa Rica.

República de Ecuador. (24 de noviembre de 2011). Decreto Ley de Fomento Ambiental y Optimización de los Ingresos del Estado. Registro Oficial № 583, Suplemento. Quito, Ecuador.

República de Ecuador. (30 de diciembre de 2011). Reglamento para la Aplicación de la Ley de Fomento Ambiental y Optimización de los Ingresos del Estado. Registro Oficial No 608, Cuarto Sumplemento. Quito, Ecuador.

Revista Semana. (6 de Abril de 2019). El mundo enfrenta la mayor contaminación del aire en 3 millones de años. Bogotá, Colombia.

San Martín, Diego (2015), El daño ambiental. Un estudio de la institución, del Derecho Ambiental y el impacto en la sociedad, Perú: Editora y Librería Jurídica Grijley.

Sánchez Gutiérrez, R., \& Villalobos González, W. (2019). Canon ambiental por vertidos en Costa Rica como instrumento económico en la gestión de aguas residuales: un enfoque metodológico y de análisis de la situación actual. Repertorio Científico, $38-49$.

Smith, S. (1998). Environmental and public finance aspects of the taxation of energy. Oxford review of economic policy, 64-83. 
UPME. (19 de 12 de 2020). Combustibles líquidos. Obtenido de Unidad de Planeación Minero Energética: https://www1.upme.gov.co/InformacionCifras/Paginas/PETROLEO.aspx

Yacolca, D. (2009), Derecho Tributario Ambiental, Perú: Editora y Librería Jurídica Grijley.

Zuñiga, D. (8 de Diciembre de 2012). Ecología: Deutsche Welle. Obtenido de Pobres resultados consiguió la Cumbre de Doha: https://www.dw.com/es/pobresresultados-consigui\%C3\%B3-la-cumbre-dedoha/a-16439413 